\title{
A ocupação urbana no Litoral Norte do Rio Grande do Sul, Brasil, e suas implicações no turismo de segunda residência
}

\author{
Urban occupation in North Coast of Rio Grande do Sul, Brazil and its \\ implications in second residence tourism
}

Eduardo Baptista Lopes, Thays Cristina Domareski Ruiz, Francisco Antonio dos Anjos

Universidade do Vale do Itajaí (UNIVALI), Balneário Camboriú, SC, Brasil

\section{Resumo}

O Litoral Norte do Estado do Rio Grande do Sul, no Brasil, é uma região que tem presenciado diversas transformações em suas formas de ocupação e expansão urbana, ao longo da história. Desde as primeiras ocupações por estâncias e fazendas até as modalidades atuais, predominantemente turísticas, os municípios desta região passaram por uma série de modificações de usos e de formas, ao longo do tempo. Este artigo tem como objetivo principal apresentar os períodos de ocupação do Litoral Norte do Rio Grande do Sul e sua relação com o turismo de segunda residência, delimitados através da identificação dos usos, da análise das formas de crescimento urbano, do traçado e das tipologias das edificações, verificados na região. Na pesquisa realizada, foi possível identificar, delimitar e analisar quatro períodos no processo de ocupação da região: estâncias e fazendas (até 1888), turismo de saúde (1888-1940), loteamentos balneários (1940-1995) e condomínios horizontais (1995-2016).

Palavras-chave: Formas de ocupação urbana. Períodos de ocupação urbana. Turismo de segunda residência. Litoral Norte do Rio Grande do Sul.

\section{Abstract}

The North Coast of Rio Grande do Sul State, Brazil, is a region in increasing urban expansion process that has been under several transformation in its forms of urban occupation and growth throughout history. Since the first occupations by ranches and farms to the current arrangements predominantly touristic, cities in this region went through a series of changes of uses and forms. This paper aims to present and analyze the periods of occupation of the North Coast of Rio Grande do Sul, and their relationship to second residence tourism, delimited by identifying the uses, analysis of the forms of urban growth, urban mesh and typology of buildings in the region. This research identified and analyzed four periods in the process of occupation of the region: ranches and farms (up to 1888), health tourism (1888-1940), coastal allotments (1940-1995) and gated communities (1995-2016).

Keywords: Urban occupation forms. Urban occupation periods. Second residence tourism. Northern Coast of Rio Grande do Sul.

EBL é arquiteto urbanista, mestre, e-mail: eduardo@arquitetoeduardolopes.com.br TCDR é turismóloga, doutora, e-mail: thaysdomareski@gmail.com FAA é geógrafo, doutor, e-mail: fanjos@terra.com.br 


\section{Introdução}

O Litoral Norte do Rio Grande do Sul é uma região com crescente processo de expansão urbana, vinculada ao crescimento demográfico, sendo sua economia baseada principalmente nas atividades de turismo e lazer (Figura 1). A sua proximidade com áreas altamente povoadas - como a região metropolitana de Porto Alegre (com 4.011.224 habitantes) e a segunda mais populosa cidade do Estado do Rio Grande do Sul fora da região metropolitana, Caxias do Sul (com 435.564 habitantes) — constitui elementos de forte influência para a apropriação desta região (IBGE, 2010).

Durante a história de sua ocupação, a região apresentou diversas fases, nas quais diferentes formas e usos predominaram. Atualmente, é possível perceber as diferentes estruturas que conformam o tecido urbano do Litoral Norte, com a presença de traçados e tipologias específicas. A identificação desses períodos de ocupação é importante para compreender as dinâmicas que levaram às formas de ocupação atual, bem como para prever as tendências de ocupação nos próximos anos.

Esta pesquisa apresenta uma análise das dinâmicas de ocupação do solo praticadas no Litoral Norte do Rio
Grande do Sul, com o objetivo de identificar os períodos de ocupação existentes e a consequente relação que mantêm com o turismo de segunda residência. Para isso, fez-se necessário a contextualização do objeto de estudo desta pesquisa, como forma de compreender suas dinâmicas territoriais e, posteriormente, reconhecer a periodização das ocupações urbanas, através do estudo das variáveis de análise urbana, as quais, neste trabalho, baseiam-se em obras de Panerai (1983), Waisman (1990), Solà-Morales (1997) e Font et al. (2007).

O Litoral do Rio Grande do Sul é conformado por uma longa faixa arenosa de $622 \mathrm{~km}$, com a ocorrência de praias, lagoas e lagunas - entre as quais, destacam-se a Laguna dos Patos e a Lagoa Mirim - , bem como a presença de cordões de dunas. Grande parte de sua área é constituída por uma das cinco unidades geomorfológicas do Estado, a Planície Costeira, que teve sua formação no período Quaternário da era Cenozoica, a mais recente da formação do planeta (SEPLAG, 2008). 0 litoral apresenta características exclusivas da região, como a faixa quase contínua de balneários, interrompidos eventualmente por rios, mas basicamente linear. Pela sua longa extensão, a Planície Costeira é uma região que se relaciona com diversas

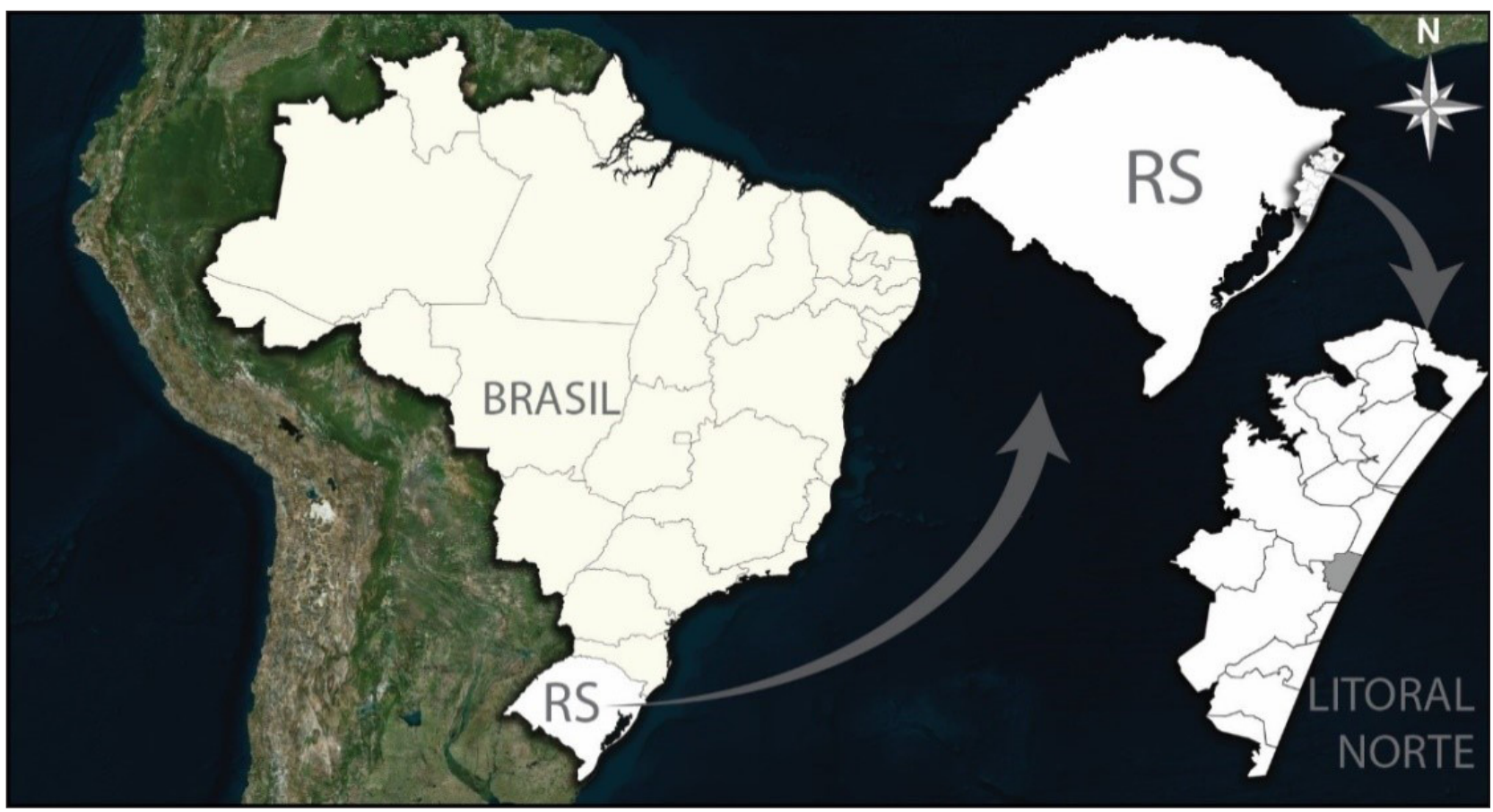

Figura 1 - Localização da área de estudo

Fonte: Base do Google Earth (2013), adaptado pelo autor. 
áreas do Estado, possuindo, portanto, diferentes dinâmicas de ocupação e uso de seu território.

Segundo Moraes (1999), as regiões litorâneas, como aspecto geográfico, são de grande importância para a sociedade moderna. 0 Brasil vem estimulando a ocupação da zona costeira brasileira a partir de duas lógicas: uma delas é o desenvolvimento de áreas portuárias e a outra está ligada à beleza cênica, que responde ao desenvolvimento do turismo. Esse estímulo se materializa em forma de infraestrutura para a ocupação e de equipamentos (Moraes, 1999).

Nesse contexto, o Litoral Norte do Rio Grande do Sul corresponde à segunda lógica citada, principalmente através da ocupação de seus balneários, cordões de dunas e de lagoas por habitações voltadas à segunda residência. Apesar da barreira representada pelo cordão de lagoas, que cruza todo o norte do Estado, a região possui uma malha viária bastante conectada, oferecendo muitas alternativas para os usuários de diversas regiões.

Dentre as principais rodovias, destacam-se a RS-486, conhecida como Rota do Sol, que liga a Serra Gaúcha ao Litoral; a BR-289, conhecida como Freeway, que liga o Município de Osório à Região Metropolitana de Porto Alegre, e a BR-101, que cruza diversos municípios do Litoral Norte e conecta o Rio Grande do Sul a diversos Estados brasileiros (Figura 2).

Além das vias de acesso que conectam a Região Metropolitana de Porto Alegre e a Serra ao Litoral Norte, outra via é de grande importância para o funcionamento e para a ligação desses municípios, a RS-389, conhecida como Estrada do Mar. Esta é

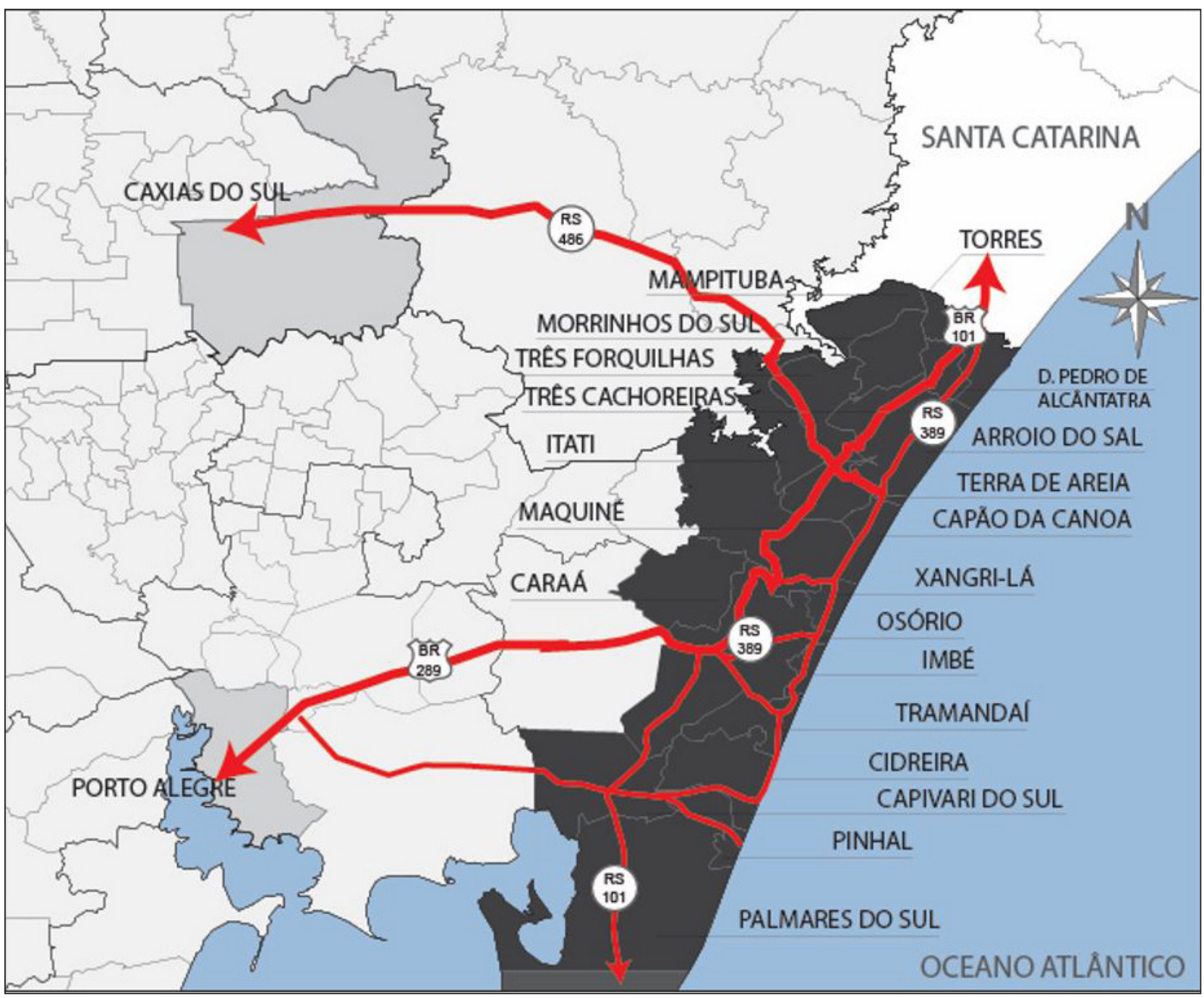

Figura 2 - Litoral Norte do Rio Grande do Sul Fonte: Elaboraç̃ão própria (2016). 
uma rodovia que liga, dentre outros balneários, as cidades de Osório, Capão da Canoa, Arroio do Sal, Torres e Xangri-Lá.

Como forma de identificar e compreender essas fases, analisam-se as formas de crescimento urbano, em que é possível definir, sob algumas variáveis, a presença dos diferentes períodos de ocupação. Foram desenvolvidos estudos de caráter exploratório, descritivo e analítico, com fundamentos teórico-conceituais, de abordagem qualitativa. Nos fundamentos teórico-metodológicos, foram reconhecidos os instrumentos para análise urbana, que tratam das formas de crescimento urbano, dos traçados e das tipologias de segunda residência.

\section{Fundamentação teórico-metodológica}

A análise da ocupação urbana é um tema abordado com frequência nos estudos urbanos, mas, segundo Panerai (1983), ocorre costumeiramente apenas em um nível muito generalizante, sob a ótica do ordenamento do território ou em um nível muito concreto, trabalhando exclusivamente com o edifício, o habitat ou os equipamentos. $\mathrm{O}$ autor ainda propõe meios de analisar as cidades mediante suas dimensões físicas, identificando alguns elementos da forma e sua organização em uma estrutura de conjunto, devolvendo à forma urbana sua possível autonomia e ampliando as explicações que se apoiam apenas em suas características funcionais e/ou econômicas. Nesse sentido, as variáveis de análise urbana que são utilizadas têm como referência principal o livro Elementos de Análisis Urbano de Panerai (1983), complementado com as propostas de Santos (1994), Solà-Morales (1997) e Font et al. (2007). As variáveis urbanas consideradas nesta pesquisa foram: as formas de crescimento, o traçado, a tipologia e a periodização.

\section{As formas de crescimento urbano}

O crescimento urbano das cidades é resultado de distintos fatores formais, sociais, econômicos e políticos, e suas relações. Panerai (1983) descreve os estudos sobre os fenômenos de crescimento, que permitem uma análise morfológica mediante uma visão global das aglomerações urbanas e de suas extensões e densificações, nas quais o estudo do crescimento mostra-se importante por:
- demonstrar uma apreensão global da aglomeração urbana em uma perspectiva dinâmica, através da identificação de períodos de ruptura e saltos no desenvolvimento e evolução da cidade, em que o estado atual é parte dessa evolução;

- revelar pontos fixos nas transformações anteriores que permitem uma compreensão da estrutura urbana e de seu funcionamento.

Panerai (1983) descreve os modos de crescimento e propõe dois tipos iniciais: o Crescimento Contínuo, caracterizado pelas extensões que, em cada etapa do desenvolvimento, ocorrem em prolongação direta das partes já construídas, e o Crescimento Descontínuo, caracterizado por cortes vegetais ou agrícolas, entre áreas novas e antigas. E sugere que esses modos de crescimento, contínuos ou descontínuos, situados ou não em um mesmo período ou em um mesmo território podem coexistir. 0 autor também aponta que essa coexistência pode traduzir-se em Justaposições ou em Conflitos.

A Justaposição ocorre quando diferentes crescimentos criam um eixo de crescimento global que não aparece ordenado, no conjunto. É um crescimento aleatório que, geralmente, não pode continuar durante muito tempo sem gerar uma perda de legibilidade da aglomeração urbana e, por vezes, graves disfunções. 0 Conflito, por sua vez, ocorre quando os diferentes crescimentos se opõem, se emaranham, se anulam, se esgotam, sem resultar numa organização do tecido. Por fim, Panerai (1983, p. 40) propõe ainda identificar as relações de crescimento entre duas classes de elementos: "[...] los que lo ordenan (Líneas y Polos de Crecimiento) y los que contienen (Barreras y Limites)".

Entre os elementos que ordenam, primeiro está o Polo de Crescimento. É o primeiro agrupamento a partir do qual se dará o desenvolvimento da aglomeração urbana, constituindo seu ponto de referência e ordenando a constituição dos crescimentos secundários. Os monumentos e cruzamentos, sejam de vias, pontes ou de pequenas povoações, podem desempenhar a função de Polo de Crescimento.

Em segundo lugar, há as Linhas de Crescimento, suportes do crescimento que ocorrem ao longo de um percurso, como vias, ruas, estradas, rios e canais. Têm como principal função ordenar o tecido, regular os crescimentos secundários e as densificações, ou seja, criar uma estrutura. 
Em relação aos elementos que contêm o crescimento, em primeiro lugar, estão os Limites de Crescimento, que constituem um obstáculo para um crescimento linear. Geralmente, um acidente sobre uma Linha de Crescimento cumpre a função de limite por certo período, até constituir-se, após esse período, em um Polo de Crescimento. São elementos que podem reverter ou modificar o crescimento, e podem ser representados por uma ponte, uma estação ou um monumento, por exemplo.

As Barreiras de Crescimento são um obstáculo para a propagação de um tecido. Podem ser obstáculos geográficos, compostos por cursos d'água, lagos e bosques, ou construídos, como fossos, canais e estradas. Em geral, são obstáculos mais permanentes, pois podem ser limites administrativos entre territórios ou zonas protegidas, por fragilidade ambiental.

Além do estudo das formas de crescimento urbano, Solà-Morales (1997) reconhece a importância do estudo das causas do crescimento, para compreender o resultado da forma urbana. Solà-Morales (1997, p. 19) aponta que "[...] toda la cuestión está em medir el tempo com el espacio", ou seja, compreender a sua dinâmica. A construção de uma cidade é uma combinação, ao longo dos anos, de suas distintas operações sobre o solo e sobre a edificação. E sua complexidade não é apenas a repetição de tipos ou de justaposição de tecidos, mas sim o processo em que cada forma e momento construtivo se sucedem, e que resultam em distâncias e continuidades, vazios e alienações, que descrevem a sequência de um processo temporal materializado em formas estáticas.

Entre as causas do crescimento, Solà-Morales (1997) as divide em duas: Causas Estruturais e Causas Indiretas. Como Causas Estruturais, há os desequilíbrios regionais de oferta e demanda de mão de obra e do mercado de trabalho, e os consequentes movimentos migratórios; há, ainda, os processos de industrialização, com o aumento do emprego industrial básico, do emprego local, população residente, serviços e emprego terciário. Como Causas Indiretas, há o mercado do solo urbano, no que se refere ao seu valor de uso e ao processo de exploração e da propriedade da terra, bem como às políticas de fomento e planejamento urbano, através de planos de ordenação e regularização, por exemplo.

Ainda segundo Solà-Morales (1997), a construção de uma cidade segue três variáveis: Parcelamento, Urbanização e Edificação. O Parcelamento refere-se à divisão e à estruturação de ocupação do solo, ou seja, a transformação do solo não urbano em urbano, pela atribuição de uso urbano. A Urbanização é a infraestrutura da estrutura de distribuição dos serviços, uma operação de construção dos elementos físicos coletivos da cidade. E, por fim, a Edificação, que é a tipologia dos edifícios.

Essas operações, entretanto, não são sempre e necessariamente simultâneas ou encadeadas de maneira igual, mas podem estar dispostas em diversas combinações no tempo e no espaço, das quais se origina a riqueza morfológica de uma cidade (Solà-Morales, 1997). A partir destas três operações, o autor indica seis combinações entre parcelamento (P), urbanização (U) e edificação (E). Dentre estas, destacam-se, no Litoral do Rio Grande do Sul, a cidade jardim e os polígonos.

A primeira forma de crescimento urbano que pode ser encontrada no Litoral Norte é a da Cidade-jardim (UP+E), que é uma ocupação predominantemente residencial, principalmente através de edificações unifamiliares, isoladas no lote e adaptadas à topografia. São, em geral, segregadas espacialmente, no sentido de que não estão ao alcance de quem ali não reside. Caracteriza-se ainda por ser uma urbanização de iniciativa privada ou cooperativa, e um projeto unitário, que define tanto as generalidades de ocupação como a densidade, os ritmos e a hierarquia, como as edificações que obedecem a modelos unifamiliares ou agrupados em poucas unidades.

Os Polígonos são grandes intervenções, nas quais as operações (PUE), para sua construção, ocorrem ao mesmo tempo. Os Polígonos possuem projeto, atuação e gestão unitária, que geram, por consequência, crescimento urbano por paquetes cerrados, bordas descontínuas, segregação e monotonia de seu interior. Entre os casos de polígonos descritos por Sola-Morales ${ }^{1}$, algumas características constantes e definições são encontradas na área de estudo da pesquisa, como a busca do solo barato, a descentralização, o perifelismo e a busca por baixa densidade. No Litoral Norte do Rio Grande do Sul, os Polígonos podem ser representados pelos condomínios horizontais, ainda que associados ao processo $\mathrm{UP}+\mathrm{E}$, pois as unidades habitacionais são iguais ou muito parecidas, o que acentua sua homogeneidade e a monotonia do seu interior.

\footnotetext{
${ }^{1}$ Em seu livro, Solà-Morales (1997) descreve os polígonos existentes em Barcelona.
} 
Outro aporte teórico que vale aqui destacar é o apresentado por Font etal. (2007), que, em seus estudos sobre a Europa Meridional, descreve a explosion de la ciudad, a última etapa do processo de urbanização, que segue lógicas de dispersão pelo território das atividades e dos fluxos, bem como a transformação interna dos núcleos urbanos.

Seus estudos trabalham com distintas escalas. $\mathrm{Na}$ escala micro, categoriza as novas formas de crescimento urbano, que respondem aos processos de urbanização atual, como territórios morfológicos. Font et al. (2007) classificam os novos territórios morfológicos em: agregados; mutações; novos assentamentos; filamentos; difusões; urbanizações; ocupações pontuais; polarizações lineares e nodais.

Esta explosão, segundo Font et al. (2007), sugere uma nova recomposição territorial das hierarquias espaciais tradicionais, através de uma forma mais generalizada e difusa nos países europeus, mas, como apontado por Anjos \& Fornara (2011), essa explosão pode ser percebida também em países americanos, particularmente no Brasil.

Os condomínios horizontais, uma das formas predominantes, atualmente, nos processos de ocupação urbana do Litoral Norte, podem ser inseridos no conceito de novos assentamentos, que os caracteriza como peças espacialmente autônomas em relação aos núcleos urbanos já existentes. Os novos assentamentos são provenientes de processos unitários de urbanização e edificação. É uma modalidade na qual surgem simultaneamente a morfologia e a tipologia. Além dos condomínios, outros espaços contemporâneos podem ser inseridos nessa categoria, como os parques tecnológicos e industriais, e outros que podem ser encontrados na área de estudo, como os parques temáticos e complexos comerciais.

Na definição sobre os novos assentamentos, de Font et al. (2007) corrobora a definição dos polígonos de Solà-Morales (1997), no que tange à forma de crescimento como um processo em que Parcelamento, Urbanização e Edificação ocorrem simultaneamente, processo este que corresponde à implantação de muitos condomínios horizontais no Litoral Norte do Rio Grande do Sul.

Neste caso, suas características se assemelham à definição de polígonos, pois além da simultaneidade de Parcelamento, Urbanização e Edificação, os condomínios possuem outros pontos em comum, como a busca do solo mais barato, uma baixa densidade populacional, verificada na maioria dos casos, e a monotonia na configuração espacial de seu interior, decorrente do processo unitário de ocupação e do padrão sociocultural dos usuários. Por fim, os condomínios assemelham-se com os polígonos porque são edificados de modo a ser segregados de seu entorno - o polígono é um loteamento acessível, mas com conexão muito frágil com a mancha urbana; o condomínio, por sua vez, está segregado pelos muros e pela descontinuidade do traçado e do tecido.

\section{Traçado}

As observações mais frequentes, ao se analisar a forma urbana, referem-se principalmente às edificações e ruas. Segundo Panerai (1983), os edifícios costumam ser caracterizados como altos ou baixos, luxuosos ou pobres, coloridos ou não. Ao passo que as ruas costumam ser descritas como ruidosas ou silenciosas, com ou sem comércios, feias ou sujas. 0 traçado, em resumo, é uma noção abstrata, e corresponde às ruas, ao espaço concreto, total e vivo.

Em uma cidade, os caminhos são os elementos fundamentais e podem ser representados por ruas, alamedas, linhas de trânsito, canais e ferrovias. Os caminhos tornam-se especialmente importantes quando concentram algum tipo exclusivo de uso, quando apresentam qualidades espaciais diferenciadas, vegetação e continuidade, além de origens e destinos claros (Lynch, 1997).

A rua e o traçado têm uma relação estreita com a criação da cidade sobre o território, ou seja, a rua relaciona-se diretamente com a formação e o crescimento da cidade, de modo hierarquizado (Lamas, 2004), em que a importância da rua se dá através de sua função de deslocação, do percurso e da mobilidade (Lynch, 1997; Lamas, 2004).

Assim, o estudo dos traçados de uma cidade é muito importante como forma de avaliar a qualidade do espaço público, uma vez que estes são elementos determinantes na configuração do urbano. Suas características físicas e os usos que abriga, bem como os pontos que os traçados conectam, podem torná-los muito importantes para a estrutura do tecido urbano. 


\section{Tipologia}

A tipologia, segundo Panerai (1983), é o estudo dos tipos e se apresenta como um instrumento, e não uma categoria, que permite dirigir o estudo dos fenômenos urbanos.

O 'tipo' é o conjunto de elementos organizados em um todo, que constitui um instrumento de conhecimento mediante 'abstração racional', que permite diferenciar categorias de objetos ou categorias de eixos (Panerai, 1983). Os tipos podem ser classificados em famílias, divididas por critérios simples, como largura, altura, ordenação, distribuição e relação com a rua. Depois de obter o tipo de cada família, é possível ilustrá-lo com um exemplo particularmente apropriado: o exemplo tipo.

Para Holanda (1985), os edifícios podem ser examinados como filtro ambiental, como modificador das condições físicas do meio físico natural e como artifício para a criação de locais confortáveis, por exemplo.

Neste sentido, o estudo dos tipos construídos é de grande importância para compreender suas relações com o espaço público e de que modo a forma de sua ocupação influencia na qualidade desse espaço. No estudo dos tipos, há a definição de tipologia edilícia, que é a tipologia dos edifícios, o conjunto dos tipos que, em uma cidade ou em um bairro determinado, permitem caracterizar o tecido construído.

Desse modo, já não constitui um fim em si mesmo e é acompanhado de uma análise dos elementos da estrutura urbana e dos processos de crescimento. Porque não se trata somente de fixar uma imagem de um momento determinado e referir-se a uma localização concreta, mas também mediante uma especial atenção às modificações que afetam a cidade ao longo do tempo e no espaço, captando as rupturas que estão na origem da formação da cidade contemporânea (Panerai, 1983).

0 estudo da relação entre os tipos construídos e a forma urbana é o meio de compreender a estrutura da cidade como continuidade histórica de um processo e como fenômeno parcial de uma totalidade; daí, a necessidade de estudar os períodos.

\section{Periodização}

Nesta pesquisa, o estudo dos períodos descreve a cidade e o urbano como espaço-tempo e trata da divisão do tempo em períodos. Segundo Santos (1994), as ideias que comandam a elaboração da história urbana são a ideia do espaço e a ideia do tempo. Pode-se trabalhar na dimensão material, que diz respeito à forma espacial, e no tempo. Os períodos são

[...] pedaços de tempo submetidos à mesma lei histórica, com a manutenção das estruturas. Estas se definem como conjuntos de relações e proporções prevalentes ao longo de um certo pedaço de tempo (Santos, 1994, p. 70).

Waisman (1990) cita que, na medida em que as ideias arquitetônicas vão se modificando e criando novas soluções, cria-se um código de elementos combináveis que respondem a uma norma sintática e a um desenvolvimento histórico. Ou seja, o período caracteriza-se pelo começo da formação dessa norma sintática até o processo de mudança para um novo conjunto de aspectos, códigos e regras, que conformam outra norma ${ }^{2}$.

Além disso, o estudo das continuidades históricas é de grande importância para a compreensão das articulações que os diferentes conjuntos urbanos apresentam, pois é, a partir da definição dessas continuidades, que podem ser identificados os períodos em que ocorrem as diferentes mudanças de desenvolvimento e direção de uma área urbana (Waisman, 1990).

E a contribuição deste estudo se dá principalmente na metodologia de construção de cada período, em que se devem buscar elementos em comum, uma combinação de aspectos que conformam o período, até a identificação de uma nova combinação que definirá outro momento histórico. Além disso, é importante identificar quais formas e estruturas espaciais perpassam os diferentes períodos de ocupação.

\section{Turismo de segunda residência}

A atividade turística exerce uma influência na organização dos espaços onde se instala, principalmente pela forma com que dinamiza as paisagens e os quadros regionais. É considerada uma modalidade de alojamento turístico, que vem crescendo nas áreas urbanas e rurais, provocando diversas transformações socioespaciais (Assis, 2003).

0 turismo de segunda residência é uma tipologia turística vinculada à hospedagem de fins de semana e

\footnotetext{
${ }^{2}$ Para Waisman (1990), esse conjunto de regras e códigos define o estilo.
} 
de temporadas de férias. A segunda residência consiste em um meio de hospedagem particular, utilizado temporariamente, nos momentos de lazer e recreação, por pessoas que têm seu domicílio permanente em outro lugar (Pearce, 1991; Tulik, 1995, 2001; Torres, 2003). A segunda residência se caracteriza por ser um fenômeno antigo e de escala mundial, que integra a oferta turística, que está compreendida nas estruturas e nos processos do desenvolvimento turístico (Pearce, 1991).

Nesse sentido, o turismo residencial pode auxiliar também no desenvolvimento de regiões, se transformando em benefícios para a localidade, onde este processo costuma estimular setores e serviços semelhantes aos que seriam incentivados pelos residentes permanentes, aumentando a base econômica da comunidade local. Pode-se também citar o aumento na arrecadação de impostos e em investimentos na região, e na demanda por produtos locais, gerando incentivo a produtores locais (Müller, 1999).

Considerando-se que o turismo de segunda residência é uma das formas utilizadas pelo turismo para a apropriação do espaço, é necessário, para a sua compreensão, considerar a totalidade das relações em que se desenvolve a atividade. Dessa forma, é muito importante definir o papel que cabe ao turismo na produção do espaço e no ordenamento e reordenamento de territórios, onde seu uso requer a consideração de inúmeras variáveis (Cruz, 2001).

Seu fundamento principal é produzir o solo urbano, construir residências e vendê-las. Nesse sentido, esta atividade inclui quatro operações: compra de solo, transformação em solo urbano, construção de residências e empreendimentos, e vendas dos mesmas (Aledo, 2008). 0 uso destas residências pode ser para os fins de semana ou como residências semipermanentes.

0 turismo de segunda residência também apresenta aspectos positivos e negativos para a localidade. Os benefícios econômicos não se restringem ao setor imobiliário. 0 turismo de segunda residência representou um impulso às finanças municipais, em função do aumento da receita de impostos e outras taxas municipais, tais como licenciamento de obras (Arrocha, 2005).

De forma a alavancar as finanças públicas, as autoridades municipais ampliam as licenças para construção. Estas novas construções demandam maiores gastos do município em infraestrutura, como, por exemplo, acessibilidade. Para cobrir estes gastos, são outorgadas mais licenças, que resultam em um círculo vicioso e que diminui a capacidade das autoridades municipais de reorientar o modelo de turismo residencial vigente (Aledo, 2004). Entretanto, também apresentam efeitos negativos, como os apartamentos, que, seguindo a lógica capitalista da produção de mercadorias, levaram a cidade a perder suas condições balneárias e a emergir como centro de comércio e serviços (Seabra, 1979).

\section{Os períodos de ocupação no Litoral Norte do Rio Grande do Sul}

Essa etapa da pesquisa busca responder à teoria de Marina Waisman (1990) e Milton Santos (1994), e utiliza como base inicial a divisão feita por Strohaecker (2007), que analisou a evolução urbana no Município de Capão da Canoa, a qual sintetiza as diversas formas de ocupações pelas quais passaram o Litoral Norte do Rio Grande do Sul. Dessa forma, apresenta-se uma periodização que coincide em alguns pontos com a base realizada por Strohaecker, principalmente nas formas de ocupação urbana dos três períodos iniciais, mas difere em outros pontos, uma vez que inclui outros municípios e identifica um quarto período de ocupação, marcado pela implantação de condomínios horizontais, principalmente no Município de Xangri-Lá.

A ocupação do Litoral Norte, de 1888 a 2013, pode ser dividida em quatro períodos (Figura 3), cujos intervalos de duração são marcados por diferentes formas de se ocupar o território, bem como sua intensidade de ocorrência. Ressalta-se, entretanto, que os usos e as formas de ocupação de cada período identificado possuem inércias que levam esses usos e formas de ocupação a perpassarem por mais de um período, com intensidades diferentes, e a coexistirem com as novas ocupações.

\section{Primeiro período de ocupação:} estâncias e fazendas (até 1888)

As primeiras ocupações são sedes de estâncias e fazendas, provenientes do parcelamento do litoral gaúcho em sesmarias pela Coroa Portuguesa. Em 1771, é fundada a Freguesia de Santo Antônio, que, mais tarde, em 1809, tornou-se o "município-mãe" do Litoral Norte, Santo Antônio da Patrulha, dando origem 


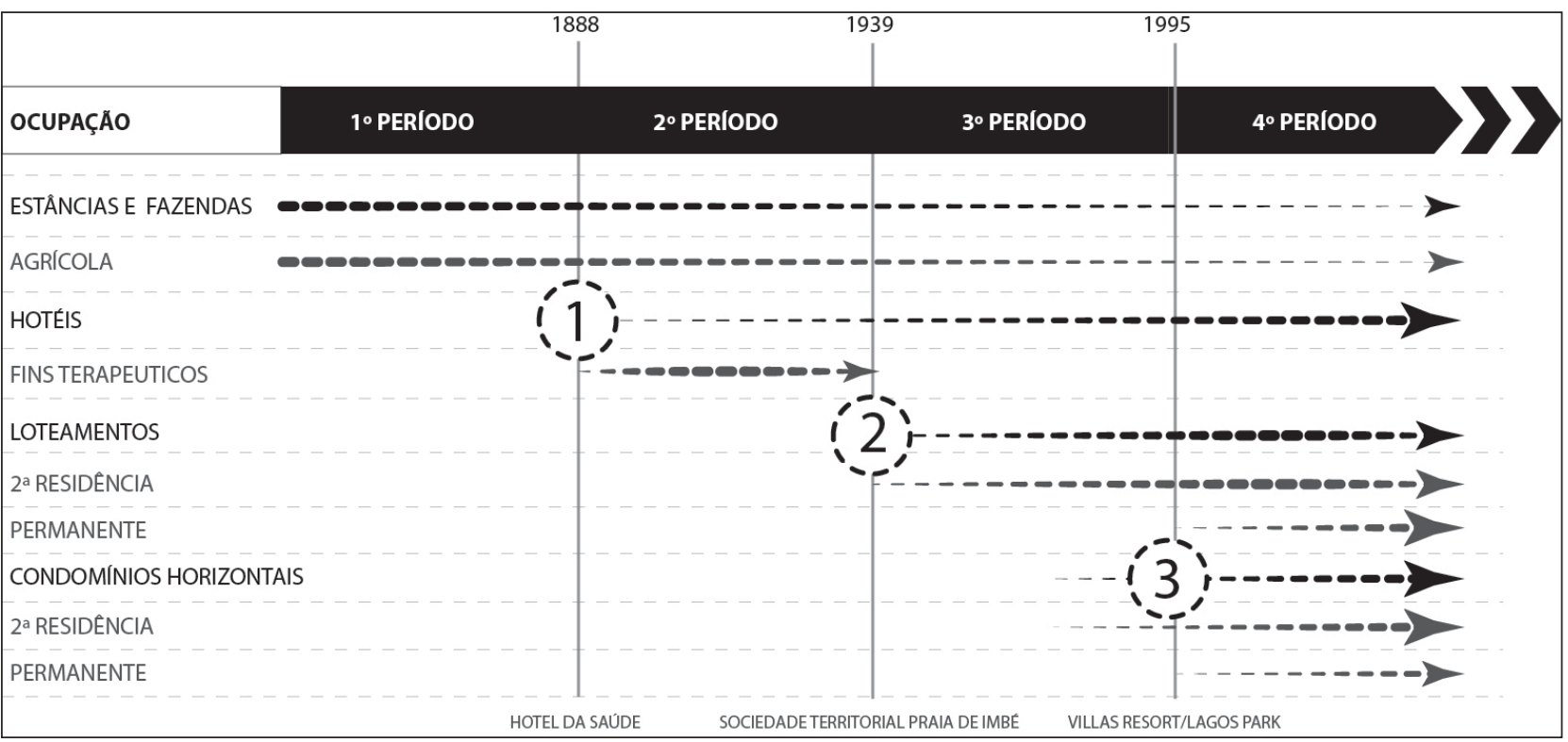

Figura 3 - Periodização do Litoral Norte do Rio Grande do Sul Fonte: Elaboracạ̃o própria, a partir de Strohaecker (2007).

aos municípios que compõem a região (Strohaecker, 2007). A economia baseava-se, então, na agricultura, na pecuária e na pesca. As estâncias e fazendas mantinham suas sedes e principais atividades em áreas mais afastadas do mar, uma vez que os recursos hídricos e o solo eram mais propícios às suas atividades, com exceção das atividades pesqueiras (Strohaecker, 2007).

Depois das ocupações por estâncias e fazendas, houve, no Brasil, um fenômeno de apropriação do mar, advindo de influências da grande imigração portuguesa no Rio de Janeiro, em 1808 (Correa, 2010). Deram-se início os banhos medicinais, que eram associados à cura de certas moléstias e aos cuidados com o corpo. No litoral do Rio Grande do Sul, iniciam-se também esses novos hábitos, provenientes da ideia de que os banhos de mar poderiam trazer benefícios terapêuticos.

Segundo período de ocupação (1888-1939): balneários para fins terapêuticos

No Estado, a atividade dos banhos de mar com motivos medicinais identifica-se com a presença dos imigrantes alemães, que, além de banhistas, destacavam-se como empresários do ramo do curismo. A ideia de usufruir o banho de mar como terapia impulsiona a instalação de pequenos hotéis e pousadas próximos à costa, que marcam a transição para o segundo período de ocupação do Litoral Norte do Rio Grande do Sul, em 1888.

A ocupação dos balneários teve grande influência da prescrição dos banhos de mar, ressaltando-se que, em 1888, na praia de Tramandaí, foi fundado o primeiro hotel de vilegiatura marítima do Rio Grande do Sul, chamado de Hotel da Saúde (Correa, 2010).

A edificação desse hotel marca a transição entre o primeiro e o segundo período de ocupação do litoral, pois é a partir deste que começam a surgir novas edificações, atrativos e infraestruturas de suporte à apropriação dessa região como balneário. 0 fluxo de curistas nos balneários gaúchos foi tanto que a companhia aérea Varig criou rotas de voos até as praias através de hidroaviões e de Junkers até Torres (Correa, 2010).

Neste sentido, foram marcantes as intervenções do Estado e as influências dos imigrantes nas políticas de modernização do Rio Grande do Sul, através das seguintes iniciativas: drenagens em pântanos; intervenções em lagoas para facilitar a navegação; abertura de estradas; fixação de dunas; arborização, e humanização dos balneários, com fins de viabilizar o usufruto da população (Correa, 2010).

A transição entre o segundo e o terceiro período aconteceu a partir da década de 1940, quando ocorreram expressivos incrementos à infraestrutura dos balneários, tanto na rede hoteleira quanto na instalação de infraestruturas de transporte. Na mesma 
década, instauraram-se as férias remuneradas para a classe trabalhadora, que passou a usufruir de forma sistemática dos veraneios nos balneários.

Esses últimos fatos deram início à democratização das praias. Seu uso não era mais restrito às classes mais abastadas e nem mais suportado apenas por hotéis. É a fase de transição para o terceiro período, em que as cidades litorâneas começaram a adquirir aspectos de segunda residência, através da ocupação massiva dos novos loteamentos.

\section{Terceiro período de ocupação (1940-1995)}

O terceiro período é marcado pelo loteamento de grandes glebas litorâneas do norte do Rio Grande do Sul, principalmente pela proximidade com os grandes núcleos urbanos do Estado, como Porto Alegre e sua Região Metropolitana, bem como com o Município de Caxias.

Esta ocupação por loteamentos representa a consolidação da ocupação urbana do Litoral Norte. A apropriação dos balneários para fins de veraneio fez com que o mercado do solo - a exploração da terra e da propriedade - ganhasse expressão, valorizando o uso do espaço para suporte de atividades urbanas e incentivando os fomentos ao planejamento urbano. Esse tipo de ocupação urbana corresponde à categoria denominada causas indiretas, proposta por Solà-Morales. A exploração dos balneários para fins de veraneio fez com que o mercado do solo ganhasse expressão, valorizando seu uso para suporte de atividades urbanas, aumentando a exploração da terra e da propriedade, e incentivando os fomentos ao planejamento urbano. Esta demanda de veranistas de forma sistemática impulsiona a atuação das agências imobiliárias que já atuavam na implantação de loteamentos, na compra e venda de lotes, e no aumento da infraestrutura urbana dos balneários (Correa, 2010).

No Brasil, a partir da década de 1940, desencadeia-se um grande processo de urbanização do território. Em 1940, o índice de urbanização era de aproximadamente $26,25 \%$, com uma população total de 41 milhões de habitantes. Já em 1980, o índice de urbanização era de $68,86 \%$, com uma população três vezes maior que quatro décadas antes, cerca de 120 milhões de habitantes (Santos, 1994).

Nas regiões litorâneas, a ocupação esteve fortemente relacionada à nova realidade estabelecida pelo governo brasileiro, através da Constituição de 1937, art. 156, que estabelecera, como já dito acima, que "[...] os funcionários terão direito a férias anuais, sem descontos, [...] com vencimentos integrais" (Brasil, 1937), garantindo, portanto, férias remuneradas, que permitiam ao trabalhador usufruir de atividades de lazer longe do centro onde vivia.

No Rio Grande do Sul, nas décadas de 1940 e 1950, antigas fazendas começam a ser parceladas e convertidas em loteamentos, para fins de segunda residência. É o caso da fazenda de Jorge José Mury, comerciante de Tramandaí e grande proprietário fundiário na região, que vende parte de suas terras para os incorporadores da Sociedade Territorial Praia de Imbé Ltda., em 1939, onde começou a ser implantado um loteamento, em 1941 (Strohaecker, 2007). Esse primeiro loteamento foi o evento que caracterizou o início desse período.

Foram dezenas de loteamentos ao longo da orla marítima, com constantes melhorias em infraestrutura e uma profunda mudança na paisagem da região. Os loteamentos implantados no Litoral Norte são, majoritariamente, de uso residencial e abrigam edificações unifamiliares isoladas nos lotes. Além disso, são decorrentes de um processo em que Parcelamento da terra e Urbanização são realizados em conjunto - como, por exemplo, o Bairro de Capão Novo - e em que as Edificações são implantadas ao longo do tempo. Dessa forma, essa ocupação possui diversos pontos em comum aos da cidade-jardim, descrita por Solà-Morales em seu livro Las formas de crecimiento urbano (Solà-Morales, 1997).

A estruturação da ocupação urbana dos municípios litorâneos deu-se de uma forma parecida, seguindo a lógica que buscava a proximidade com o mar. A Figura 4 sintetiza a estrutura da forma urbana da ocupação do Litoral Norte gaúcho, onde diversos loteamentos começaram a ser implantados de maneira espaçada.

Dessa maneira, os loteamentos caracterizavam-se, inicialmente, como um Crescimento Descontínuo, já que existiam cortes vegetais e agrícolas entre as áreas mais novas e as áreas mais antigas, além de possuírem um Limite de Crescimento, representado pela praia. Esse limite foi a base para a implantação das principais avenidas, que eram paralelas ao mar. Os crescimentos, portanto, seguiam através de uma Linha de Crescimento, representada, por exemplo, pela Avenida Paraguassú (Figura 4). Essa avenida surgiu com o loteamento que deu origem ao Município de Capão da Canoa, na década de 1940 (Strohaecker, 2007) e, 


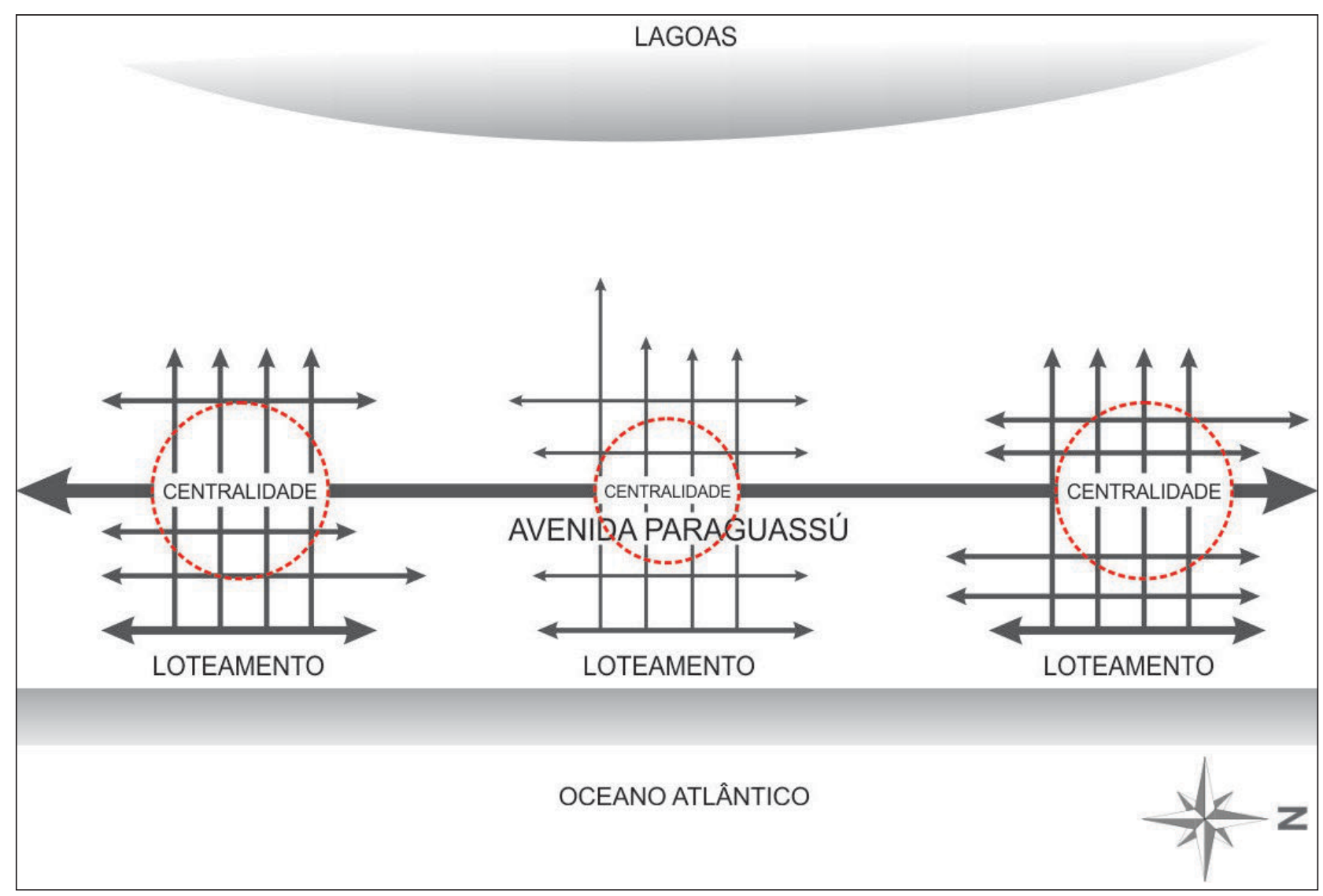

Figura 4 - Ocupação dos municípios do Litoral Norte do Rio Grande do Sul Fonte: Elaboraçãoo própria (2013).

atualmente, conecta os principais municípios litorâneos do Norte do Estado. É através dessa Avenida que os loteamentos cresceram inicialmente, atingindo uma conurbação quase total.

No processo de ocupação do Litoral Norte, figura um outro eixo viário importante na formação de sua paisagem. No final da década de 1980, deu-se início à construção da RS-389, conhecida popularmente como Estrada do Mar, que liga os municípios entre Osório e Torres. Essa estrada, concluída no início da década de 1990, representou um novo agente de crescimento da ocupação urbana, ampliando a acessibilidade no Litoral Norte como um todo, até então concentrada pela BR-101.

A partir da Estrada do Mar, surgem novos acessos aos municípios e é principalmente no encontro desses acessos com a Avenida Paraguassú que se concentram, com maior intensidade, as centralidades urbanas dos municípios. Com o aumento de mobilidade proveniente da consolidação dos acessos, essas áreas passaram a concentrar as maiores densidades de ocupação, bem como abrigar os principais edifícios administrativos dos municípios, além de concentrar estabelecimentos de consumo, como shoppings centers, redes de lojas de eletrodomésticos e móveis, entre outros.

A centralidade urbana identificada pode ser relacionada à capacidade que alguns espaços ou elementos urbanos têm de articular fluxos de qualquer natureza. A intensidade da articulação está relacionada ao grau de influência desses espaços com os demais componentes do sistema urbano (Licnerski, 2008 apud Assen de Oliveira, 2011).

Essas duas vias são, desse modo, as principais estruturantes e indutoras do crescimento da ocupação e, mesmo tendo classificações diferentes - uma estrada, outra avenida - ambas desempenham uma função crucial na dinâmica da ocupação urbana e da paisagem das cidades do Litoral Norte do Rio Grande do Sul.

Neste sentido, é possível observar que o turismo de segunda residência foi identificado na área de estudo. Destaca-se que pode ser facilmente observada uma 
produção imobiliária crescente de condomínios de veraneio como residências secundárias.

\section{Quarto período de ocupação (1995-2016): condomínios horizontais}

Para a compreensão e identificação do quarto período, é necessário destacar que, de uma maneira geral, a sociedade atual está passando por uma nova fase da modernidade, chamada terceira fase. Esse fenômeno aprofunda as três características socioantropológicas presentes no processo de modernização: a individualização, a racionalização e a diferenciação social (Ascher, 2004). Na terceira fase da modernidade, essas dinâmicas, principalmente as da individualização e de diferenciação social, parecem ter muita força de transformação nas formas de ocupar o território. Podem resultar numa ocupação urbana dispersa, que agrega diversas características sociais, de acessibilidade de bens e de serviços que diferem das ocupações mais compactas.

No Brasil, esses processos de diferenciação social e individualização afirmam existir segregação dos espaços coletivos por grupos sociais, tornando-os exclusivos a estes grupos. É através dessa tendência à segregação que são criados circuitos de consumo exclusivo, como os parques de lazer, os shoppings centers e os condomínios horizontais. Neste sentido, na sociedade brasileira, ocorre um forte processo de valorização dos espaços privados e de enfraquecimento e esquecimento dos espaços públicos. As relações sociais estão cada vez menos voltadas ao bem-estar coletivo, e o individualismo vem tornando-se o modo de vida praticado pela maioria. Isso é visto seguidamente nas novas formas de ocupação urbana (Serpa, 2007).

Esse processo de segregação, presente na maioria das cidades brasileiras, também pode ser verificado em cidades com viés turístico, de lazer e veraneio, como no caso das cidades do Litoral Norte do Rio Grande do Sul. As classes de mais alta renda trazem consigo essas formas de ocupação urbana, que vêm tornando-se recorrentes na região. Esse crescimento se dá através de urbanizações mais dispersas sobre o território, em condomínios horizontais, ou concentradas em áreas de grande valorização imobiliária, como condomínios verticais com frente ou próximos ao mar.

Depois da conclusão da Estrada do Mar, em 1991, o crescimento urbano dos municípios litorâneos, antes voltados para o mar, nesse período, aponta para outra direção. A ocupação passa a ocorrer ao longo das avenidas de acesso criadas entre a rodovia e os bairros através dessa nova forma de crescimento, que responde à definição de Polígono, de Solà-Morales, e de novo assentamento, de Font et al. (2007). Além disso, pode-se fazer uma relação conceitual entre o modelo espacial destes condomínios - polígonos e novos assentamentos - cujo interior tenta repetir o conceito de cidade-jardim, através de habitações unifamiliares dispostas em grandes áreas verdes e com baixas densidades de ocupação.

A implantação de condomínios horizontais nessa região se intensificou a partir da segunda metade da década de 1990, principalmente no Município de Xangri-Lá. A partir do ano de 1995, ocorre um crescimento acelerado na implantação de condomínios, impulsionados principalmente pela conclusão, em 1991, da Estrada do Mar, rodovia que liga as principais praias do Norte do Estado. Sua construção foi um marco importante na consolidação dessa modalidade de habitação. Entre os anos de 1995 e 2013, mais de 40 condomínios foram construídos ou estão em processo de conclusão, nessa região.

Muitos desses condomínios estão sendo implantados em regiões afastadas do mar. Isso ocorre pelo fato de que a maioria das áreas próximas ao mar já são ou já estão sendo consolidadas, e também ao custo do solo, que é mais barato, afastado da linha litorânea. Atualmente, os condomínios que estão sendo instalados adjacentes à Estrada do Mar concentram-se principalmente próximos aos acessos e, em alguns pontos, são voltados para as lagoas. A paisagem natural, dessa forma, passou a ser revalorizada, incorporando, além do mar, a beleza cênica das lagoas, das dunas e dos campos, principalmente para as atividades de lazer, recreação e turismo, que são apropriadas pelos padrões espaciais dos condomínios.

Assim, ao contrário dos loteamentos que buscavam a proximidade com o mar, os condomínios, por possuírem estruturas de lazer próprias, podem ocupar áreas de fácil acesso, como entradas da cidade, nós viários e proximidade com a Estrada do Mar.

Dentre os municípios que compõem o Litoral Norte do Rio Grande do Sul, Xangri-Lá tem sua área territorial correspondente a $60,68 \mathrm{~km}^{2}$ (IBGE, 2010) e foi o que recebeu a maior parte dos investimentos em condomínios horizontais. Desde os primeiros condomínios da região, implantados em 1995, surgem, 
no município, outros 27 condomínios, até o ano de 2013. Em sua extensão territorial, aproximadamente 11,4 km² $(18,78 \%)$ são ocupados por urbanizações tradicionais, correspondentes aos loteamentos que ocorreram durante o Terceiro período. Além dessa ocupação, é possível ver, na Figura 5, a área ocupada por condomínios, que correspondem a aproximadamente $6,4 \mathrm{~km}^{2}$, ou seja, $10,54 \%$ do território.
Os condomínios horizontais em Xangri-Lá possuem características predominantemente de segunda residência, voltados para oferecer uma alternativa de lazer para quem mora nas grandes cidades, como Porto Alegre, e são, muitas vezes, temáticos. Esses condomínios trazem consigo reproduções de estilos arquitetônicos, tipologias de ocupação interna e atividades específicas, como marinas e campos de

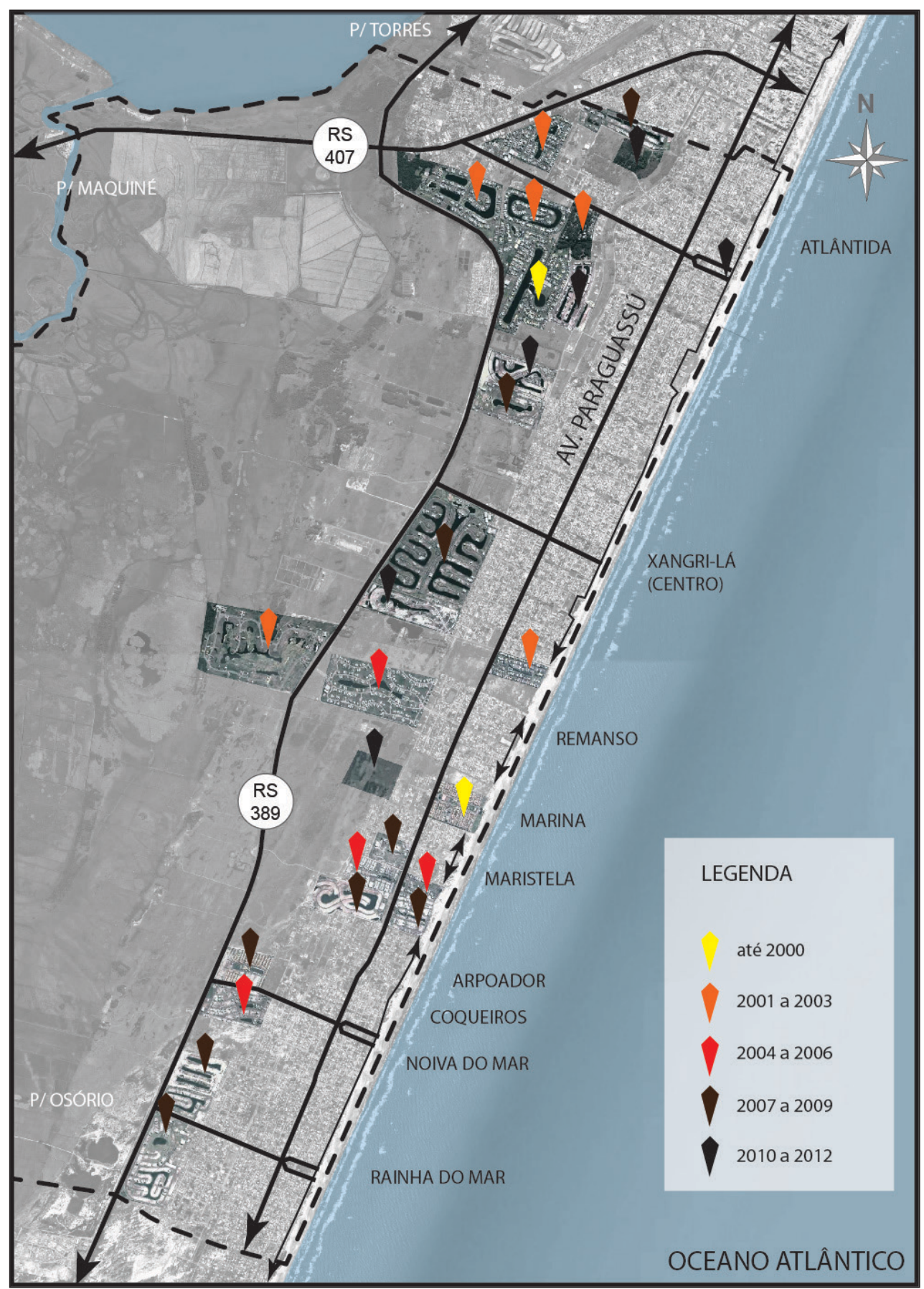

Figura 5 - Condomínios horizontais de Xangri-Lá

Fonte: Base do Google Earth (2013), adaptado pelo autor.

urbe. Revista Brasileira de Gestão Urbana (Brazilian Journal of Urban Management), 2018 maio/ago., 10(2), 426 -441 
golfe. São os chamados country clubs (Chevalier \& Carballo, 2005).

A implantação de condomínios, que atualmente ocorre na faixa entre a ocupação tradicional, próxima da praia, e a Estrada do Mar, pode ser confirmada por informações provenientes da Secretaria de Planejamento da Prefeitura Municipal de Xangri-Lá ${ }^{3}$, que indica que os vazios ainda existentes nessa área serão ocupados por condomínios e que, após o fechamento completo, a tendência é que os investimentos migrem para o outro lado da estrada.

Pode ser evidenciada, no terceiro período de ocupação, uma valorização dos espaços litorâneos como áreas de lazer, recreação e turismo, o que levou à implantação de loteamentos e empreendimentos imobiliários para fins de segunda residência, condomínios e loteamentos em áreas privilegiadas pela beleza cênica (Strohaecker, 2007).

\section{Considerações finais}

O Litoral Norte do Rio Grande do Sul passou por diversas fases de ocupação, cada uma com suas dinâmicas de usos e formas. Mesmo assim, é possível perceber que o terceiro e o quarto período de ocupação, correspondentes aos loteamentos e aos condomínios horizontais, respectivamente, são os crescimentos urbanos mais significativos e que estruturam os principais municípios do Litoral Norte, sobretudo Xangri-Lá (Lopes, 2013). É a partir do período dos loteamentos que surgem os principais eixos viários dos municípios e é quando se desenvolvem as primeiras centralidades e as principais vias que conduzem o crescimento das cidades. Neste momento, é possível ser observado o início do processo de ocupação de segundas residências.

Foi possível constatar que a ocupação por condomínios horizontais é uma tendência que perdurará por um

\footnotetext{
${ }^{3}$ Informações provenientes de uma entrevista realizada por e-mail, no dia 2 de Setembro de 2013, com o Técnico da Secretaria de Planejamento do Município de Xangri-Lá. Na entrevista, o Técnico diz que

[...] o que ocorre hoje é a expansão da ocupação pelos condomínios fechados [sic] nas áreas livres entre o limite oeste dos balneários e a estrada do mar [sic]... em poucos anos a "fachada" de xangri-lá [sic] para a estrada do mar [sic] será apenas muros... e depois disso, vão querer ocupar o outro lado da estrada [...].
}

considerável período de tempo. Isso pôde ser confirmado, ao longo da pesquisa, através de entrevistas realizadas com a Secretaria de Planejamento da Prefeitura Municipal de Xangri-Lá e em matérias encontradas em jornais locais, que afirmam a clara preferência dos usuários por veranear nos condomínios, nesta região. Além disso, é possível constatar, através da cronologia das imagens de satélite, que, em áreas onde existem condomínios, a construção de habitações em loteamentos está estagnada (Lopes, 2013).

Este fenômeno pode ser relacionado ao que Ascher denomina de terceira fase da modernidade, em que a busca pela individualização do espaço e a diferenciação social tornam-se um modo de vida a ser alcançado. Os condomínios horizontais verificados representam uma urbanização dispersa e segregadora.

Estas diferentes modalidades de ocupação, em geral dispersas sobre o território, podem acarretar diversos impactos econômicos e sociais, e sobremaneira impactos na qualidade dos espaços públicos de seu entorno, uma vez que estas usualmente adotam formas espaciais que se fecham para o exterior. As extensas áreas ocupadas geram descontinuidades urbanas e ilhas ao longo do território, que podem acarretar diminuição na vitalidade da cidade, bem como causar problemas ambientais, já que substituem o ecossistema original, possuem altos custos de infraestrutura e ocupam o solo com densidades baixas.

0 turismo de segunda residência foi identificado, nesta pesquisa, pela voracidade que dinamiza e altera as paisagens e os quadros regionais (Tulik, 2001; Assis, 2003), em que a paisagem como um recurso turístico está sendo transformada pelo turismo de segunda residência. Assim, a expansão urbana para segunda residência e a implantação de equipamentos turísticos estão entre os principais vetores do processo de ocupação da zona costeira brasileira (Brasil, 2006). Nesse sentido, o turismo de segunda residência vem acarretando uma crescente urbanização e expansão turística, principalmente no litoral Norte do Rio Grande do Sul, causando mudanças na paisagem e de ecossistemas, já que estes empreendimentos se localizam em zonas costeiras. A busca do lazer, do descanso, da proximidade maior com elementos da natureza, sejam estes relacionados ao mar ou à vegetação, se constitui em um dos motivos para o deslocamento das residências permanentes e, neste caso, verifica-se aqui uma contradição entre o uso da praia como lugar de grande socialização, com a presença de uma diversidade de usuários (econômica 
e cultural), e o modelo de condomínios, que evidencia uma grande segregação físico-espacial.

0 que pode ser observado no processo como um todo é que esses impactos são resultados visíveis da falta de planejamento tanto dos agentes envolvidos neste processo como do poder público que, facilitando a entrada de investidores com a justificativa de tornar sua região mais competitiva, se abstém dos aspectos relacionados ao território, permitindo a atuação desenfreada por parte da especulação imobiliária. Esta, por sua vez, comercializa o atrativo natural sem a preocupação dos efeitos que causa no espaço onde esses empreendimentos se reproduzem.

\section{Referências}

Aledo, A. (2004). Turismo y desarrollo: una reflexión sobre las teorías del post-desarrollo. In A. M. Nogués (Eds.), Cultura y turismo. Sevilla: Signatura Demos.

Aledo, A. (2008). De la tierra al suelo: la transformación del paisaje y el nuevo turismo residencial. Arbor Ciencia, Pensamiento y Cultura, 184(729), 99-113.

Anjos, F. A., \& Fornara, R. A. (2011). Morfologia da cidade contemporânea: os novos territórios morfológicos de Itajaí (SC). In L. A. Oliveira, G. P. A. Amaral e Silva, \& A. M. Rossetto (Eds.), Arquitetura da cidade contemporânea: centralidade, estrutura e políticas públicas (pp. 211-226). Itajaí: UNIVALI.

Arrocha, A. (2005). La hacienda local en los destinos turísticos: el caso de Torrevieja. In T. Mazón, \& A. Aledo (Eds.), Turismo residencial y cambio social. Alicante: CAM-UA.

Ascher, F. (2004). Los nuevos principios del urbanismo. Madrid: Alianza Editorial.

Assen de Oliveira, L. (2011). Caminhos da Centralidade na cidade contemporanea: um jogo de escalas. In L. A. Oliveira, G. P. A. Amaral e Silva, \& A. M. Rossetto (Eds.), Arquitetura da cidade contemporânea: centralidade, estrutura e políticas públicas (pp. 21-46). Itajaí: UNIVALI.

Assis, L. F. (2003). Turismo de segunda residência: a expressão espacial do fenômeno e as possibilidades de análise geográfica. Revista Território, 7(11-13), 107-122.

Brasil. (1937, 10 de novembro). Constituição dos Estados Unidos do Brasil. Brasília: Diário Oficial da União.
Brasil. (2006). Projeto orla: manual de gestão (88 p.). Brasília: MMA, MPOG.

Chevalier, J., \& Carballo, C. (2005). Los espacios cerrados residenciales: en busca del entre-sí; estudio comparativo entre el norte y el sur del continente americano. Cuadernos de Geografia, 14, 5-14.

Correa, S. M. S. (2010). Germanidade e banhos medicinais nos primórdios dos balneários no Rio Grande do Sul. História, Ciências, Saúde, 17, 165-184.

Cruz, R. C. A. (2001). Introdução à geografia do turismo. São Paulo: Roca.

Font, A., Carracedo, O. \& Vesclir, L. (2007). Configuraciones Metropolitanas: estructura espacial y tipos de crecimiento urbano. In A. Font (Ed.), La explosión de la ciudad. Madrid: Ministerio de Vivienda.

Google Earth. (2013). Recuperado em 5 de setembro de 2013, de https://www.google.com.br/intl/pt-BR/earth

Holanda, F. R. (1985). Arquitetura como Estruturação Social. In R. L. Farret (Ed.), O espaço da cidade: contribuição à análise urbana. São Paulo: Parma.

Instituto Brasileiro de Geografia e Estatística - IBGE. (2010). Censo demográfico de 2010. Rio de Janeiro. Recuperado em 10 de março de 2017, de http://www.ibge.gov.br

Lamas, J. M. R. G. (2004). Morfologia urbana e desenho da cidade (3a ed.). Porto: Fundação Calouste Gulbekian.

Lopes, E. B. (2013). Os condomínios residenciais e suas relações espaciais com o entorno: o caso de Xangri-Lá/RS (Dissertação de mestrado). Programa de Pós-graduação em Urbanismo, História e Arquitetura da Cidade, Universidade Federal de Santa Catarina, Florianópolis.

Lynch, K. (1997). A imagem da cidade. São Paulo: Edições 70. Moraes, A. C. R. (1999). Contribuições para a gestão da zona costeira do Brasil: elementos para uma Geografia do Litoral Brasileiro. São Paulo: Hucitec.

Müller, D. (1999). German second home owners in the Swedish countryside: on the internationalization of the leisure space. Umeå: Department of Social and Economic Geography.

Panerai, P. (1983). Elementos de analisis urbano. Madrid: Fareso.

Pearce, D. G. (1991). Tourism today: a geographical analysis. New York: Longman.

Santos, M. (1994). A urbanização brasileira (2a ed.). São Paulo: Hucitec. 
Seabra, O. C. L. (1979). A muralha que cerca o mar: uma modalidade de uso do solo urbano (Dissertação de mestrado). Faculdade de Filosofia, Letras e Ciências Humanas, Universidade de São Paulo, São Paulo.

Secretaria de Planejamento e Gestão Cidadã - SEPLAG. (2008). Atlas Socioeconômico do Rio Grande do Sul. Porto Alegre. Recuperado em 10 de março de 2017, de http:// www.seplag.rs.gov.br/

Serpa, A. (2007). O espaço público na cidade contemporânea. São Paulo: Contexto.

Solà-Morales, M. (1997). Las formas de crecimiento urbano. Barcelona: Edicions UPC.

Strohaecker, T. M. (2007). A urbanização no litoral Norte do Rio Grande do Sul: contribuição para a gestão urbana ambiental do município de Capão da Canoa (Tese de doutorado). Programa de Pós-graduação em Geociências, Universidade Federal do Rio Grande do Sul, Porto Alegre.

Torres, B. E. (2003). El Turismo residenciado y sus efectos en los destinos turísticos. Estudios Turísticos, 155(6), 45-70.

Tulik, O. (1995). Residências secundárias: presença, dimensão e expressividade do fenômeno no Estado de São Paulo (Tese de livre-docência). Escola de Comunicações e Artes, Universidade de São Paulo, São Paulo.

Tulik, O. (2001). Turismo e meios de hospedagem: casas de temporada (113 p.). São Paulo: Roca.

Waisman, M. (1990). El interior de la historia: historiografia arquitectonica para uso de latinoamericanos. Bogotá: Escala.

Recebido: Mar. 10, 2017

Aprovado: Jul. 26, 2017 